DEPARTAMENTO DE ZOOTECNIA

Diretor: Prof. Dr. João Soares Veiga

\title{
UTILIZAÇÃO DO NITROGÊNIO, CĀLCIO E FÓSFORO, DE MISTURA COMERCIAL, BALANCEADA (Dog Meal), NO CÃO *
}

\author{
(NITROGEN, CALCIUM AND PHOSPHORUS UTILIZATION FROM \\ COMMERCIAL DIET IN DOGS)
}

\section{Fernando ANdreasi}

Assistente

\section{INTRODUCAAO}

Como complemento ao estudo da digestibilidade da mistura comercial, balanceada, efetuado por ANDREASI (1956), e dada a intima relação existente entre digestāo e metabolismo, provas de balanço dos elementos nitrogênio, cálcio e fósforo, foram realizadás.

O gráu de utilização de dada proteína alimentar sòmente poderá ser julgado através dos estudos de balanço. Uma proteina é tanto mais completa quanto menor fôr a quantidade necessária para manter o animal em equilibrio nitrogenado.

As primeiras provas nesse sentido foram descritas por VoIT (1868) [cit. MCCAY: 64 (1949)].

O valor biológico da proteina, ou mais corretamente, do nitrogênio total da ração é expresso como a porcentagem de nitrogênio absorvido que ć realmente retida no organismo [Mitchell (1924a)].

Mrtchell (1924a), em ratos, propôs método fundamental de determinaçāo do valor biológico das proteinas, baseado no balanço do nitrogênio e, o mesmo autor (1924b), aplicou-o para comparar o valor das proteínas quando administradas em diferentes teôres de ingestão.

Com a introdução das chamadas dietas purificadas, Rose (193738) chegou a estabelecer classificação dos aminoácidos essenciais e as quantidades exigidas para o normal crescimento de ratos.

* Trabalho realizado na Universidade de Cornell (Ithaca, N.Y.) por especial deferência da Rockefeller Foundation. 
Melnick e Cowgill (1937) estudaram, em cães, os teôres minimos necessários de lactoalbumina, sôro-proteina, caseina e gliadina para a mantença do equilibrio nitrogenado nessa espécie.

Os estudiosos no assunto orientaram seus trabalhos no sentido de esclarecer o papel de cada um dos aminoácidos essenciais e nāo essenciais, como também as quantidades e interrelações existentes, para as exigências alimentares dos ratos (ROSE e RICE, 1939; RoSE e colabs., 1948).

ROSE e RICE (1939), desta feita, empregando cães como animais de experimentação, precisaram a importância fisiológica dos aminoácidos. A remoção de quaisquer dêstes compostos da dieta, era seguida, invàriavelmente, de pronunciado balanço nitrogenado negativo. Estes achados, aduziram os autores, demonstraram que as necessidades qualitativas do cão, em relação aos aminoácidos, são idênticas às do rato.

MADDEN e colabs. (1943) trabalhando com cães, empregaram aminoácidos essenciais quer adicionados à ração, quer administrados parenteralmente, após depleção total da proteina do plasma sangüíneo. Quando a proteína ingerida era completa sob o aspecto dos aminoácidos, a recuperação da proteína do plasma era excelente, ao mesmo tempo que o pêso corporal e balanço nitrogenado eram mantidos.

Elman e colabs. (1945) verificaram, em cães, em cuja dieta figuravam $80 \%$ de carboidratos e $20 \%$ de proteina, que o equilibrio nitrogenado foi alcançado sòmente em um animal, quando as calorias fornecidas eram mantidas ao nivel de 50 calorias por quilo de pêso vivo. Todavia, a redução para 25 calorias/kg determinava balanço negativo em ambos os animais constituintes do par. Por outro lado, a composição inversa da ração - $80 \%$ de proteína e $20 \%$ de carboidratos -, determinou balanço positivo, apesar de os animais ingerirem apenas 25 calorias por quilo. Concluiram então que a proporção de quatro partes de proteina para uma parte de carboidratos deve ser indicada em raçōes de baixo conteúdo energético.

KADE e colabs. (1948), estudaram também em cães, o valor biológico de várias proteínas e estabeleceram, através de provas de balanço, as quantidades minimas necessárias das mesmas, para manter o animal em equilibrio nitrogenado.

Udall e MCCAY (1953) estudaram a possibilidade de aproveitar o ôsso fresco como provedor de proteina para rações destinadas a cães. Conquanto tivessem encontrado balanços nitrogenados negativos, acharam que a proteina do ôsso cru parece ser de superior qualidade à da gelatina que é notòriamente pobre como fonte de proteína. 
Lloyd e MCCAY (1955) fizeram, além dos estudos da digestibilidade, provas de balanço do nitrogênio. Os cāes jovens fixaram, em relação aos adultos e idosos, mais nitrogênio, enquanto êstes últimos, exceção feita a duas dietas, revelaram capacidade mais acentuada de fixar o nitrogênio do que os adultos.

Por outro lado, a atenção dos experimentadores no campo da nutrição tem sido dirigida, principalmente, para o papel do cálcio e fósforo no desenvolvimento do esqueleto dos animais em crescimento.

A maioria dos trabalhos registrados na literatura, diz respeito a experiências realizadas com animais de laboratório e em fase de crescimento.

Autores há - Kauffmann e Roche (1926), em cães, Adolph e Liang (1941), em ratos - que focalizaram o problema da eliminaçāo do cálcio atendo-se mòrmente, na porção designada de cálcio metabólico.

Medes (1926), haAg e Palmer (1928), Campbell e colabs. (1935), DuYne e colabs. (1941), em ratos, referiram-se aos valores de cálcio e fósforo na dieta, estabelecendo relações entre o pêso do esqueleto e fixação dos mesmos no organismo.

No homem, CuthBertson (1929) havia estudado a influência do prolongado descanso muscular sôbre o metabolismo dêsses elementos.

NICOLAYSEN (1937), em ratos, chamou a atençāo sôbre a importância da vitamina $\mathbf{D}$ na ração e sua conseqüente influência na retenção do cálcio e fósforo no organismo.

HALnI e colabs. (1939) abordaram o assunto sob o aspecto da influência exercida pelos teôres excessivos de cálcio e fósforo na dieta, sôbre a eliminação dos mesmos pelos excretas.

Tisdall e DRAKe (1938), cm ratos, estudaram a importância da relaçāo cálcio e fósforo na dicta.

LAWRENZ e MiTCHELL (1941), em ratos, reportaram-se aos niveis de cálcio e fósforo na raçāo, relacionando-os com o pêso do esqueleto c consequientes reflexos nos teôres de cinzas, cálcio e fósforo nos ossos.

LOVELACE c colabs. (1950), em ratos, abordaram os efeitos da adição de oxalato às dietas contendo teôres normais de cálcio e ressaltaram o fator idade no aproveitamento do cálcio dietético.

Pinkos (1952) assinalou a influência do exercicio, em cães Dinamarqueses (Great Dane) na absorção do cálcio e determinou os niveis ótimos de cálcio, fósforo $e$ vitamina $D_{2}$ na dieta. 
Ainda Lru e McCay (1953) compararam o metabolismo do cálcio em cães jovens e adultos, assim como estudaram, em cães Cockers o efeito do exercicio sôbre a absorçāo do cálcio.

UdALl e MCCAY (1953) utilizaram o ôsso fresco, sob diversos tratamentos, com o fito de obter fonte eficiente de cálcio e fósforo, como suplemento às raçōes para cães.

LLOYd e MCCAY (1955) verificaram tambẻm em cães, que os jovens exibiram maior capacidade de retenção do cálcio e fósforo, oriundos de seis dietas contendo teôres variáveis dêsses elementos.

\section{DETERMINAÇAO DO BALANÇO DO NITROGENIO, CÁlCIO E FÓSFORO} NA ESPECIE CANINA

\section{MATERIAL E MÉTOdO}

Os mesmos cāes e a mistura balanceada utilizados para os estudos da digestibilidade, referidos por ANDREASI (1956), foram objeto das provas de balanço do nitrogênio, cálcio e fósforo.

1 - Colheita de urina - A urina foi colhida diàriamente, segundo técnica já descrita [ANDREASI (1956)] e transferida para proveta, a fim de medir-se o volume total. Para os animais adultos, a amostra representativa tomada eqüivalia a $10 \%$ do total excretado e, para os jovens, foi recolhido volume equivalente a $20 \%$. As amostras eram guardadas em vidro de bôca larga, com tampa de pressão, e contendo $10 \mathrm{ml}$ de ácido sulfúrico concentrado e mantidas em refrigerador.

2 - Preparo da urina para análise - Métodos de oxidação úmida, semelhantes à digestão pelo método de KJELDAHL são preferiveis aos processos de incineração usuais, devido às dificuldades na obtenção e dissolução das cinzas.

A técnica por nós seguida pode ser assim delineada:

a) transferir $100 \mathrm{ml}$ de urina para béquer de $250 \mathrm{ml}$ de capacidade;

b) adicionar $15 \mathrm{ml}$ da seguinte mistura:

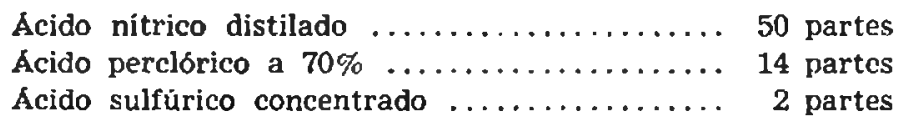

c) cobrir o béquer com vidro de relógio e reduzir o volume em chapa aquecida, situada em capela de boa tiragem; medidas de proteção pessoal devem ser tomadas nesta fase; 
d) juntar, seguidamente, $20 \mathrm{ml}$ da mistura à medida que o volume se reduz;

e) obtida a completa oxidação, traduzida pelo aparecimento de resíduo branco, retirar o vidro de relógio e proceder, em chapa aquecida, à evaporação dos ácidos que compōem a mistura;

f) acrescentar $10 \mathrm{ml}$ de ácido cloridrico $2 \mathrm{~N}$ destilado e dissolver o resíduo em banho a vapor;

g) transferir para frasco volumétrico de $50 \mathrm{ml}$ de capacidade e completar o volume com água bi-destilada. Dêste modo obtém-se a chamada solução "A".

Not八 - Insistir no tratamento pela mistura e observar suave aquecimento no decorrer da digestão.

Ao se proceder às diluiçōes com ácido cloridrico diluido, obtém-se, vez ou outra, residuos de coloração amareláda, demonstrando incompleta digestão. Nestes casos, evaporar o ácido cloridrico e voltar ao tratamento pela mistura, até completa oxidaçāo.

3 - Métodos analiticos - $\mathrm{O}$ nitrogênio e cálcio foram determinados pelos métodos oficiais A.O.A.C. (1945) e o fósforo pelo método de Fiske e SubBarow (1925).

Nota - O cálcio na urina foi determinado pelo micro-método segundo técnica descrita em A.O.A.C. (1945).

As proporçōes dos elementos nitrogênio, cálcio e fósforo, presentes na ração, fezes e urina, são encontradas na tabela $I$.

Tabela I - Composição química da ração, fezes e urina.

\begin{tabular}{|c|c|c|c|c|c|c|c|c|c|}
\hline \multirow{3}{*}{ 苞 } & \multicolumn{6}{|c|}{ Sôbre matéria sêca $(\mathrm{mg} / 100 \mathrm{~g})$} & \multirow{2}{*}{\multicolumn{3}{|c|}{ Urina }} \\
\hline & \multicolumn{3}{|c|}{ R a çã o } & \multicolumn{3}{|c|}{ Fezes } & & & \\
\hline & $\mathbf{N}$ & $\mathrm{Ca}$ & $\mathbf{P}$ & $\mathbf{N}$ & $\mathrm{Ca}$ & $\mathbf{P}$ & $\stackrel{N}{N}$ & $\begin{array}{c}\mathrm{Ca} \\
(\mathrm{mg} / 100 \mathrm{ml})\end{array}$ & $\underset{(\mathrm{mg} / 100 \mathrm{ml})}{\mathbf{P}}$ \\
\hline 1 & 5009 & 1475 & 995 & 5170 & 6331 & 3282 & 1365 & 1,9 & 118,7 \\
\hline 2 & 5009 & 1475 & 995 & 4963 & 6715 & 4191 & 1298 & 1,7 & 116,2 \\
\hline 3 & 5009 & 1475 & 995 & 5218 & 6673 & 3441 & 1239 & 2,9 & 95,6 \\
\hline 4 & 5009 & 1475 & 995 & 5525 & 6339 & 3596 & 1062 & 5,0 & 105,3 \\
\hline 5 & 5009 & 1475 & 995 & 5592 & 4905 & 2815 & 969 & 0,8 & 115,0 \\
\hline 6 & 5009 & 1475 & 995 & 6102 & 4875 & 2770 & 682 & 0,8 & 84,4 \\
\hline 7 & 5009 & 1475 & 995 & 5472 & 5005 & 2490 & 792 & 1,4 & 113,1 \\
\hline 8 & 5009 & 1475 & 995 & 5799 & 4942 & 2678 & 606 & 4,8 & 64,4 \\
\hline
\end{tabular}




\section{RESULTADOS}

Os resultados concernentes aos balanços do nitrogênio, cálcio e fósforo figuram, respectivamente, nas tabelas II, III e IV.

Tabela II - Balanço do nitrogênio.

\begin{tabular}{|c|c|c|c|c|c|c|c|}
\hline \multirow{2}{*}{ Animal } & \multirow{2}{*}{$\begin{array}{l}\text { Pêso } \\
\text { vivo } \\
(\mathrm{kg})\end{array}$} & \multicolumn{5}{|c|}{$\mathrm{mg} / \mathrm{kg} / \mathrm{dia}$} & \multirow{2}{*}{$\begin{array}{c}\text { Retenção } \\
(\%)\end{array}$} \\
\hline & & Ingerido & Fezes & Urina & Balanço & $\begin{array}{l}\text { fixada } \\
\text { (Nx6,25) }\end{array}$ & \\
\hline 1 & 11,0 & 1053 & 305 & 559 & 189 & 11,8 & 17,9 \\
\hline 2 & 11,7 & 990 & 257 & 523 & 210 & 13,1 & 21,2 \\
\hline 3 & 9,4 & 1232 & 363 & 644 & 225 & 14,1 & 18,3 \\
\hline 4 & 9,5 & 1219 & 385 & 636 & 198 & 12,4 & 16,2 \\
\hline 5 & 3,7 & 1565 & 447 & 372 & 746 & 46,6 & 47,7 \\
\hline 6 & 3,2 & 1809 & 651 & 633 & 525 & 32,8 & 29,0 \\
\hline 7 & 3,8 & 1524 & 384 & 570 & 570 & 35,6 & 37,4 \\
\hline 8 & 4,4 & 1316 & 382 & 701 & 233 & 14,6 & 17,7 \\
\hline
\end{tabular}

Tabela III - Balanço do cálcio.

\begin{tabular}{|c|c|c|c|c|c|c|}
\hline \multirow{2}{*}{ Animal } & \multirow{2}{*}{$\begin{array}{c}\text { Pêso vivo } \\
\text { (kg) }\end{array}$} & \multicolumn{4}{|c|}{$\mathrm{mg} / \mathrm{kg} / \mathrm{dia}$} & \multirow{2}{*}{$\begin{array}{c}\text { Retenção } \\
(\%)\end{array}$} \\
\hline & & Ingerido & Fezes & Urina & Balanço & \\
\hline 1 & 11.0 & 310 & 374 & 1 & -6.5 & $-21,0$ \\
\hline 2 & 11,7 & 291 & 348 & 1 & -58 & $\ldots 19,9$ \\
\hline 3 & 9.4 & 363 & 464 & 1 & -102 & $-28,1$ \\
\hline 4 & 9,5 & 359 & 442 & 3 & -86 & $--23,9$ \\
\hline 5 & 3,7 & 461 & 392 & $\mathbf{0}$ & +69 & $+15,0$ \\
\hline 6 & 3,2 & 533 & 521 & 1 & -11 & †. 2,1 \\
\hline 7 & 3.8 & 449 & 351 & 1 & +97 & $-21,6$ \\
\hline 8 & 4,4 & 387 & 326 & 1 & +60 & $+15,5$ \\
\hline
\end{tabular}


Tabela IV - Balanço do fósforo.

\begin{tabular}{c|c|c|c|c|c|c}
\hline \multirow{2}{*}{ Animal } & $\begin{array}{c}\text { Pêso vivo } \\
(\mathrm{kg})\end{array}$ & \multicolumn{4}{|c|}{$\mathrm{mg} / \mathrm{kg} / \mathrm{dia}$} & $\begin{array}{c}\text { Retenção } \\
(\%)\end{array}$ \\
\hline 1 & 11,0 & 209 & 194 & 49 & -34 & $-16,3$ \\
2 & 11,7 & 196 & 217 & 47 & -68 & $-34,7$ \\
3 & 9,4 & 245 & 239 & 50 & -44 & $-17,9$ \\
4 & 9,5 & 242 & 251 & 63 & -72 & $-29,7$ \\
5 & 3,7 & 311 & 225 & 44 & +42 & $+13,5$ \\
6 & 3,2 & 359 & 296 & 78 & -15 & $--4,2$ \\
7 & 3,8 & 303 & 175 & 81 & +47 & $+15,5$ \\
8 & 4,4 & 261 & 176 & 74 & +11 & $+4,2$ \\
\hline
\end{tabular}

\section{DISCUSSAO}

Depreende-se da tabela II que os animais mostraram balanço nitrogenado positivo, mòrmente aquêles em crescimento corroborando os valores de LLOYd e MCCAY (1955). A percentagem de fixação do nitrogênio no organismo - 18,4\% para os adultos e $32,9 \%$ para os jovens se processou mais uniformemente para os adultos, muito embora as ingestões de nitrogênio por quilo de pêso vivo dos cães jovens tivessem sido mais elevadas. Não obstante, as diferenças, entre idades, revelaram-se não significantes, estatisticamente.

Face a êstes resultados, a ração por nós empregada, contendo $31,3 \%$ de proteina, com digestibilidade média de $70,2 \%$ e, relação nutritiva 1:2,9 [ANDREASI (1956)], se mostrou inteiramente satisfatória sob o ponto de vista do teor de nutrientes plásticos.

Referimo-nos a propósito da digestibilidade da raçāo, ora em estudo [ANDREASI (1956)], que os animais adultos digeriram aproximadamente a metade do teor de cinzas contido na ração, em relação aos jovens. Este achado vem corroborar nossos resultados do balanço do cálcio e fósforo - tabelas III e IV - pois, os animais adultos apresentaram balanço negativo.

LLOYD e MCCAY (1954) não referiram dados atinentes ao balanço dêsses elementos, porém, seus resultados relativos à digestibilidade das cinzas colidiram inteiramente com os nossos valores. Somente provas de balanşo dêsses minerais poderiam confirmar suas conclusões. 
Todavia, em trabalho recente, LLoYd e MCCAY (1955), utilizando não só idêntica ração comercial, ora estudada por nós, como também animais da mesma raça e idade, reforçam nossas conclusōes, isto é, de que os cães jovens têm capacidade mais acentuada de aproveitar o cálcio e fósforo na dieta, do que a apresentada pelos adultos.

Deixamos contudo de cotejar nossos resultados com os dos citados autores em virtude dêstes últimos nāo terem consignado, em seu trabalho, os pêsos dos animais estudados.

LIU e McCAy (1953), fizeram estudos sôbre o metabolismo do cálcio, usando animais de pequeno porte, e de raças diversas, verificando que a fixaçāo do cálcio no organismo tende a decrescer da décima-quarta à vigésima semana de idade. Os valores percentuais de retenção exibidos pelos citados autores são da ordem de $23 \%$ e $10 \%$ para os cães de 20 semanas de idade, e pesando, respectivamente, 7 a 8 quilos.

Para os cães Beagle, de 12 semanas, seus resultados figuram ao lado dos dados obtidos por nós (tabela $V$ ).

Tabela V - Comparaçāo de balanços do cálcio e fósforo entre os dados de Liu e McCay c os do Autor.

\begin{tabular}{|c|c|c|c|c|c|c|c|c|c|c|c|c|}
\hline \multicolumn{6}{|c|}{ Liu e McCay (1953) } & \multirow{3}{*}{ 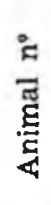 } & \multicolumn{6}{|c|}{ Dados do Autor } \\
\hline \multicolumn{2}{|c|}{$\begin{array}{c}\text { Dieta } \\
(\%)\end{array}$} & \multicolumn{2}{|c|}{$\begin{array}{l}\text { Ingerido } \\
\text { (mg/kg/dia) }\end{array}$} & \multicolumn{2}{|c|}{$\begin{array}{c}\text { Balanço } \\
\text { (mg/kg/dia) }\end{array}$} & & \multicolumn{2}{|c|}{$\begin{array}{c}\text { Dieta } \\
(\%)\end{array}$} & \multicolumn{2}{|c|}{$\begin{array}{l}\text { Ingerido } \\
(\mathrm{mg} / \mathrm{kg} / \mathrm{dla})\end{array}$} & \multicolumn{2}{|c|}{$\begin{array}{c}\text { Balanço } \\
(\mathrm{mg} / \mathrm{kg} / \mathrm{dla})\end{array}$} \\
\hline $\mathrm{Ca}$ & $\mathbf{P}$ & $\mathrm{Ca}$ & $P$ & $\mathrm{Ca}$ & $\mathbf{P}$ & & $\mathrm{Ca}$ & $P$ & $\mathrm{Ca}$ & $P$ & $\mathrm{Ca}$ & $P$ \\
\hline 0,56 & 0,38 & 391 & 268 & 199 & 110 & 5 & 1,47 & 0,99 & 461 & 311 & 69 & 42 \\
\hline 0,55 & 0,78 & 394 & 558 & 245 & 124 & 6 & 1,47 & 0,99 & 533 & 359 & 11 & 15 \\
\hline 0,57 & 1,48 & 421 & 1091 & 202 & 255 & 7 & 1,47 & 0,99 & 449 & 303 & 97 & 47 \\
\hline 0,57 & 2,23 & 405 & 1589 & 209 & 416 & 8 & 1,47 & 0,99 & 387 & 261 & 60 & 11 \\
\hline
\end{tabular}

Verificamos (tabela $V$ ) que as raçōes de ambos os grupos comparados forneceram, em $\mathrm{mg} / \mathrm{kg} / \mathrm{dia}$, teores elevados de cálcio e fósforo.

Entretanto, nos jovens, o cálcio e o fósforo disponiveis na ração por nós estudada, mostraram niveis de aproveitamento extremamente baixos. Enquanto as proporçōes de cálcio ingerido foram aproximadamente comparáveis ảs conferidas por LIU e MCCAY (1953), nossos animais ingeriram, relativamente reduzida taxa de fósforo. 
Segundo trabalho dos citados autores, parece, todavia, que as relações cálcio-fósforo, nos jovens, não exerceram influêneia na assimilação do cálcio, uma vez que variando de 1,5:1 a 1:3,9 nāo determinaram oscilaçōes notórias no bálanço dêsse elemento, mas, ao contrário, o aumento do teor de fósforo na dieta, em relação ao cálcio, provocou aproveitamento mais acentuado do fósforo.

Por outro lado, conquanto nossos animais adultos ingerissem teôres suficientes de cálcio e fósforo contidos na dieta cuja relação cálciofósforo era adequada $(1,5: 1)$, os valores negativos observados no balanço dêsses elementos (tabelas III e IV) poderiam, possivelmente, ser atribuidos ao baixo conteúdo de vitamina $\mathrm{D}$ existente em nossa dieta $0,075 \%$ - em contraste ao alto nivel de $3 \%$ da ração utilizada por LIU e MCCAY (1953).

Diante dèsses resultados, parece que os animais adultos têm menor capacidade de aproveitar os elementos minerais, em presença de baixo teor de vitamina $D$.

Convém ressaltar, entretanto, que as dietas aplicadas por LiU e MCCAY (1953), eram constituidas de compostos purificados, portanto, de fácil digestibilidade e, conseqüentemente, de assimilação.

Não obstante, nossos resultados são reforçados pela maioria dos dados contidos no trabalho de LIU e MCCAY (1953).

Entretanto, os limites mínimos encontrados por êstes autores, ou seja, $86 \mathrm{mg}$ ou pouco acima de $100 \mathrm{mg} / \mathrm{kg} /$ dia para os mais idosos, não foram confirmados por nós, muito embora os aludidos autores tivessem trabalhado com cães de idade avançada. Os animais adultos estudados por nós, ingeriram, em média, $331 \mathrm{mg} / \mathrm{kg} /$ dia de cálcio e, $223 \mathrm{mg} / \mathrm{kg} /$ dia de fósforo e, no entretanto, mantiveram balanços negativos. Éstes resultados convertidos em porcentagem, sāo da ordem de $-23,2 \%$ para o cálcio e $-24,6 \%$ para o fósforo.

Nos jovens, a ingestão média foi de $457 \mathrm{mg}$ e $308 \mathrm{mg} / \mathrm{kg} / \mathrm{dia}$, respectivamente, para o cálcio e o fósforo, determinando balanço positivo de cêrca de $13,5 \%$ para o cálcio e $7,2 \%$ para o fósforo.

Elevado é o número de fatôres tidos como capazes de influenciar a absorção do cálcio e fósforo, fatôres êsses que, agindo isoladamente ou em conjunto, poderiam explicar o deficiente aproveitamento dêsses minerais da ração utilizada neste experimento. Entre êles, podem ser citados:

a) Teor de alimento consumido. 


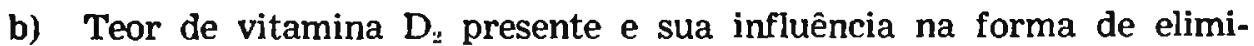
nação dêsses elementos nos cães jovens ou adultos [SchMidT e GREenberG (1935) ].

c) Balanço ácido-básico na dieta e seus efeitos sôbre o $\mathrm{pH}$ intestinal [PINkos (1952)].

d) A funçāo normal da paratiróide [Darling (1937)].

e) A adição de cloreto de sódio à dieta [RICHARd e colabs. (1924)], influenciando a assimilação do cálcio no organismo.

f) A presença de cereais determinando açāo anti-calcificante [MELLANBY e PATTISON (1932)].

g) A solubilidade dos sais presentes na ração [SCHMIDT e GREENBERG (1935) ].

h) A natureza da dieta com predominância de grãos, mostrou em porcos, decréscimo progressivo de retenção de cálcio e fóstoro [HUSBAND e colabs. (1923)].

i) A influência da fibra bruta sôbre a digestibilidade da raçāo com repercussōes na assimilação do cálcio e fósforo [HaLlsworth (1949) $)$.

A deficiente assimilação do cálcio e fósforo observada na ração empregada por nós, em cotejo com a dieta utilizada por LiU e MCCAY (1953), pode ser posta em evidência, segundo os dados da tabela que se segue:

Tabela VI - Dados comparativos dos teôres, cm mg de cálcio é fósforo, excretados por $100 \mathrm{mg}$ de cálcio ingerido.

\begin{tabular}{c|c|c|c|c|c}
\hline \multicolumn{2}{c|}{ Liu e McCay (1953) } & \multicolumn{3}{c|}{ Dados do Autor } \\
\hline $\begin{array}{c}\text { Idade } \\
\text { (semanas) }\end{array}$ & Cálcio & Fósforo & $\begin{array}{c}\text { Idade } \\
\text { (semanas) }\end{array}$ & Cálcio & Fósforo \\
\hline \hline & & & & & \\
12 & 49 & 59 & 16 & 85 & 86 \\
12 & 38 & 78 & 16 & 98 & 104 \\
12 & 52 & 77 & 16 & 78 & 84 \\
12 & 48 & 74 & 16 & 84 & 96 \\
\hline
\end{tabular}

A simples inspeção da tabela VI sugere - dentre outras possibilidades já enumeradas - que o baixo nivel de aproveitamento poderia também ser atribuido à forma sob a qual foram oferecidos os compostos minerais. 
Cumpre assinalar, entretanto, que para fixar, inicialmente, a quantidade máxima de alimento que seria distribuida aos animais, foi tomado como critério, o pêso de ração consumida, pronta e completamente, pelo animal menos voraz, de cada idade. Nessas condições, os dados negativos consignados teriam sido, provàvelmente, menos acentuados se os cães mais vorazes tivessem tido, à disposição, quantidade maior de ração.

A falta de exercício do animal, apontada como causa determinante da menor assimilação de cálcio e fósforo [PINkos (1952), LIU e MCCAY (1953) no cão, e JoHnSToN (1950) em crianças sãs e portadoras de tuberculose pulmonar 1, teria contribuido também, com sua parcela, para a baixa assimilação dêsses dois elementos nos adultos.

Entretanto, os resultados obtidos pelos diversos autores, no que tange ao papel do exercício na fixação do cálcio, ainda são inconcludentes e sugerem ulteriores estudos, no sentido de esclarecer a influência do mesmo sôbre a assimilação do cálcio nos animais de diferentes idades, estado de nutrição e outras condições.

\section{CONCLUSOES}

1) A porcentagem de fixaçāo do nitrogênio no organismo - 18,4\% para os adultos e $32,9 \%$ para os jovens - conferiu à mistura comercial, balanceada (Dog Meal), qualidades plásticas apreciáveis.

2) Embora apresentando altos niveis de ingestão, os cães adultos, recebendo $1,47 \%$ de cálcio e $0,99 \%$ de fósforo, não conseguiram equilibrar as necessidades dêsses elementos no organismo. Esta conclusão vem reforçar os dados de ANDREASI (1956), de que os animais adultos têm menor capacidade de digerir as cinzas.

3) Os animais jovens, todavia, mostraram capacidade mais acentuada de utilizar o cálcio e fósforo disponiveis da ração, naquelas proporçōes, de sorte a apresentarem balanços positivos dêsses elementos.

\section{RESUMO}

Estudou-se neste trabalho, o balanço do nitrogênio, cálcio e fósforo de mistura comercial, balanceada (Dog Meal).

O teor de 31,3\% sôbre matéria sêca (ANDREAsı, 1956), de proteína presente na ração, demonstrou ser adequado para as necessidades de crescimento e de mantença dos cães estudados. Os animais, adultos e jovens, apresentaram balanço positivo com referência a êsse elemento. 
Todavia, no que se refere aos elementos cálcio e fósforo, embora tivessem os animais adultos ingerido quantidades suficientes dêsses elementos e relação cálcio-fósforo adequada, não conseguiram atingir o nivel de aproveitamento condizente com suas necessidades. A ingestāo de $331 \mathrm{mg}$ e de $223 \mathrm{mg} / \mathrm{kg} / \mathrm{dia}$, respectivamente, para o cálcio e fósforo, nos adultos, determinou balanço negativo da ordem de $-23,2 \%$ para o cálcio e de $-24,6 \%$ para o fósforo.

Por outro lado, os jovens mostraram capacidade mais acentuada de retirar da ração, os minerais necessários para estabelecer balanço positivo. Os jovens ingeriram, em média, $457 \mathrm{mg}$ e $308 \mathrm{mg} / \mathrm{kg} /$ dia, respectivamente, para o cálcio e fósforo e apresentaram balanço positivo de cêrca de $13,5 \%$ para o cálcio e $7,2 \%$ para o fósforo.

\section{SUMMARY AND CONCLUSIONS}

After looking over the literature concerning the nitrogen, calcium and phosphorus retention, in various animal species, balance studies were made in dogs using a commercial ration (Dog meal).

It was found that $31.3 \%$ protein, and nutritive ratio 1:2.9 (ANDREASI, 1956) were satisfactory for the growth maintenance requirements of the dogs studied. Both, adults - about two years old - and young - sixteen weeks old - presented nitrogen positive balance. The differences between ages were significant.

However, concerning the calcium and phosphorus elements, the adults dogs could not set up positive balance in spite of the fact that they ingested sufficient amounts of both elements and in proper ratio as well. The intake amounts of $331 \mathrm{mg} / \mathrm{kg}$ of calcium and $223 \mathrm{mg} / \mathrm{kg}$ of phosphorus in adults, daily, determined $-23.2 \%$ for the calcium and $-24.6 \%$ for the phosphorus or, in other words, they presented negative balances.

On the other hand, the young dogs showed higher hability to draw from the ration, the mineral elements necessary to set up positive balance.

The young dogs, on the average, ingested $457 \mathrm{mg} / \mathrm{kg}$ of calcium and $308 \mathrm{mg} / \mathrm{kg}$ of phosphorus, daily, and presented positive balance of about $13.5 \%$ for calcium and $7.2 \%$ for phosphorus.

\section{BIBLIOGRAFIA}

AdolpH, W. H. and Ch.-Ch. LiANG - 1941 - Calcium in the alimentary tract of the rat. J. Biol. Chem., 197(2):517-23 
ANDREASI, F. - 1956 - Estudo de métodos indiretos (Óxido crômico e lignina) para a determinação da digestibilidade aparente no cão. Dađos não publicados. Fac. Med. Vet. Univ. S. Paulo (Tese)

Association of Official Agricultural Chemists - 1945 - Official and tentative methods of analysis; 6th ed. Washington, George Banta Publishing Co.

Campbell, H. L., O. A. Bessey and H. C. Silerman - 1935 - Adult rats of low calcium content. J. Biol. Chem., 110(3):703-6

Cuthbertson, D. P. - 1929 - The influence of prolonged muscular rest on metabolism. Biochemical J., 23(2):1328-45

Darling, E. R. - 1937 - The place of calcium in the diet of the dog. North Am. Vet., $18(5): 43-7$

Duyne, F. O. V., C. S. Lanford, E. W. Toepfer and H. C. Sherman - $1941-$ Life time experiments upon the problem of optimal calcium intake. $J$. Nutrition, 21 (3):221-4

Elman, R., H. W. DAVEY and R. KIYASU - 1945 - Nitrogen balance on a restricted caloric intake. J. Lab. and Clin. Med., 30(3):273-7

Fiske, C. H. and J. SubBarow - 1925 - The colorimetric determination of phosphorus. J. Biol. Chem., $66: 375-80$

HAaG, J. R. and L. S. PAlmer - 1928 - The effect of variations in the proportions of calcium, magnesium, and phosphorus contained in the diet. $J$. Biol. Chem., 76(2):367-89

HALd, J., G. BACHMANN, W. WYNN and Ch. ENSOR - 1939 - The effects produced by an increase in the calcium and phosphorus content of the diet on the calcium and phosphorus balance and on various bodily constituents of the rat. J. Nutrition, $18(4): 339-409$

Hallsworth, E. G. - 1949 - The relationship between the crude-fiber content of pasture and other feeding-stuffs and their digestibility and starch equivalent. J. Agric. Sci., $39(3): 254-8$

Husband, A. D., W. Godden and M. B. Richards - 1923 - The influence of cod-liver oil, linsced oil and olive oil on the assimilation of calcium and phosphorus in the growing pig. Biochemical J., 17:707-19

Johnston, J. A. - 1950 - Factors influencing retention of nitrogen and calcium in period of growth. VIII: Influence of rest and activity. Am. J. Dis. Children, 80(4):551-65

Kade, C. F. Jr., J. H. Pilllits and W. A. Phillips - 1948 - The determination of the minimum eitrogen requirement of the adult dog for maintenance of nitrogen balance. J. Nutrition, 36(1):109-21

KauffmanN, C. O. et J. Roche - 1926 - Influence de la nature de l'alimentation proteique sur l'climination du calcium. Compt. Rend. Soc. Biol., 95(23):351-2

LAWRenz, M. and H. H. Mitchell - 1941 - The effect of dietary calcium and phosphorus on the assimilation of dietary fluorine. J. Nutrition, 22(1) :91-101

LIT, C. H. and C. M. MCCAY - 1953 - Studies of calcium metabolism in dogs. J. Gerontology, $8(3): 264-71$.

Lloyd, L. E. and C. M. McCAY - 1954 - The use of chromic oxide in digestibility and balance studies with dogs. J. Nutrition, 53(4):613-22 
LLOYD, L. E. and C. M. MCCAX - 1955 - The utilization of nutrients by dogs of different ages. J. Gerontology, $10(2): 182-87$

LOVELACE, F. E., C. H. LIU and C. M. MCCAY - 1950 - Age of animals in relation to the utilization of calcium and magnesium in the presence of oxalates. Arch. Biochem., 27(1):48-56

Madden, S. C., J. R. Carter, A. A. Kattus Jr., L. L. Miller and G. H. Whipple 1943 - Ten amino-acids essential for plasma protein production effective orally or intravenously. J. Exp. Med., $77(3): 277-95$

McCAY, C. M. - 1949 - Nutrition of the dog; 2nd. ed. Ithaca, N.Y., Comstock Publishing Co. Inc.

Medes, G. - 1926 - Rats on diets high in phosphorus and low in calcium. Proc. Soc. Exp. Biol. \& Med., 23(8):679

Mellanby, M. and C. L. Pattison - 1932 - The influence of a cereal-free diet rich in vitamin $\mathrm{D}$ and calcium on dental caries in children. Brit. Med. J., $\mathbf{l}: 507-10$

Melnick, D. and G. R. Cowgrll - 1937 - The protein minima for nitrogen equilibrium with different proteins. J. Nutrition, 13(4):401-24

Mitchell, H. H. - 1924(a) - A method for determining the biological value of protein. J. Biol. Chem., $68(3): 873-903$

Mitchell, H. H. - 1924(b) - The biological value of proteins at different levels of intake. J. Biol. Chem., 58(3):905-22

NicolaySEN, R. - 1937 - Studies upon the mode of action of vitamin D. II: The influence of vitamin $D$ on the faecal output of endogenous calcium and phosphorus in the rat. Biochemical J., \$1(1):107-21

Prnkos, J. A. - 1952 - Calcium and phosphorus metabolism studies on Great Dane dogs. Thesis P.H.D. at Cornell University. Ithaca, N.Y.

Richards, M. B., W. Godden and A. D. Husband - 1924 - The influence of variation in the sodium-potassium ratio on the nitrogen and mineral metabolism of the growing pig. Biochemical $J$., 18(3-4):651-60

Rose, W. C. - 1937 - The nutritive significance of the amino acids and certain related compounds. Science, 86(2231):298-300

Rose, W. C. - 1938 - The nutritive significance of the amino acids. Physiol. Reviews, $18(1): 109-36$

Rose, W. C. and E. E. RICE - 1939 - The significance of the amino acids in canine nutrition. Science, $90(2330): 186-7$

Rose, W. C., M. J. Oesterling and M. Womack - 1948 - Comparative growth on diets containing ten and nineteen amino acids, with further observations upon the role of glutamic and aspartic acids. J. Biol. Chem., 176(2):753-62

SchMidT, C. L. A. and D. M. Greenberg - 1935 - Occurrence, transport and regulation of calcium, magnesium, and phosphorus in the animal organism. Physiol. Reviews, 16(3):412

Tisdall, F. F. and T. G. H. Drake - 1938 - The utilization of calcium. J. Nutrition, 16(6):613-20

UdAll, R. H. and C. M. MCCAY - 1953 - The feed value of fresh bone. $J$. Nutrition, 49(2):197-208 